\title{
Uterine differentiation as a foundation for subsequent fertility
}

\author{
F. F. Bartol ${ }^{1}$, A. A. Wiley ${ }^{1}$, J. G. Floyd ${ }^{1}$, T. L. Ott ${ }^{2}$, F. W. Bazer' ${ }^{2}$, \\ C. A. Gray ${ }^{2}$ and T. E. Spencer ${ }^{2}$ \\ 'Department of Animal and Dairy Sciences, Auburn University, AL 36849-5415; and 'Institute of \\ Biosciences and Technology, Center for Animal Biotechnology, Texas A \& M University, \\ College Station, TX 77843-2471, USA
}

\begin{abstract}
Uterine differentiation in cattle and sheep begins prenatally, but is completed postnatally. Mechanisms regulating this process are not well defined. However, studies of urogenital tract development in murine systems, particularly those involving tissue recombination and targeted gene mutation, indicate that the ideal uterine organizational programme evolves epigenetically through dynamic cell-cell and cell-matrix interactions that define the microenvironmental context within which gene expression occurs and may ensure adult tissue stability. In the cow and ewe, transient postnatal exposure of the developing uterus to steroids can produce immutable changes in adult uterine tissues that may alter the embryotrophic potential of the uterine environment. Thus, success of steroid-sensitive postnatal events supporting uterine growth and development can dictate the functional potential of the adult uterus. Studies to determine effects of specific steroidal agents on patterns of uterine development during defined neonatal periods, as well as the functional consequences of targeted neonatal steroid exposure in the adult uterus, should enable identification of critical developmental mechanisms and determinants of uterine integrity and function. Extreme adult uterine phenotypes (lesion models) created in cattle and sheep by strategic postnatal steroid exposure hold promise as powerful tools for the study of factors affecting uterine function and the rapid identification of novel uterine genes.
\end{abstract}

\section{Introduction}

The uterus is an essential reproductive organ. Functions of the uterus in domestic ruminants include generation of the luteolytic signal required for ovarian cyclicity, transport and maturation of spermatozoa, recognition and reception of embryos, provision of an embryotrophic environment for conceptus development, and expulsion of the fetus and placenta at parturition (Bartol, 1999). These functions are borne by the uterine mucosa or endometrium and smooth muscle or myometrium. Developmental determinants of uterine function are not well defined. However, studies of laboratory animals (Mori and Nagasawa, 1988), humans (Mori and Nagasawa, 1988, Cooper and Kavlock, 1997), wildlife species (Cooper and Kavlock, 1997), and domestic ungulates, including sheep (Bartol et al., 1988a, 1997), cattle (Hancock et al., 1994; Bartol et al., 1995; King et al., 1995; Bartol et al., 1996; Bartol and Floyd, 1996) and pigs (Bartol et al., 1993), indicate that exposure of developing uterine tissues to agents that disrupt critical organizational events can have lasting effects on reproductive health. Thus, while genetic potential for uterine competence and reproductive success may be defined at conception, success of developmental events regulating uterine growth, morphogenesis and cytodifferentiation ultimately determines phenotypic potential of the uterus to support essential reproductive processes.

The fact that disruptive effects of steroids can have long-term consequences for uterine function, and that the nature of such effects reflects specific conditions of steroid exposure, suggests a strategy 


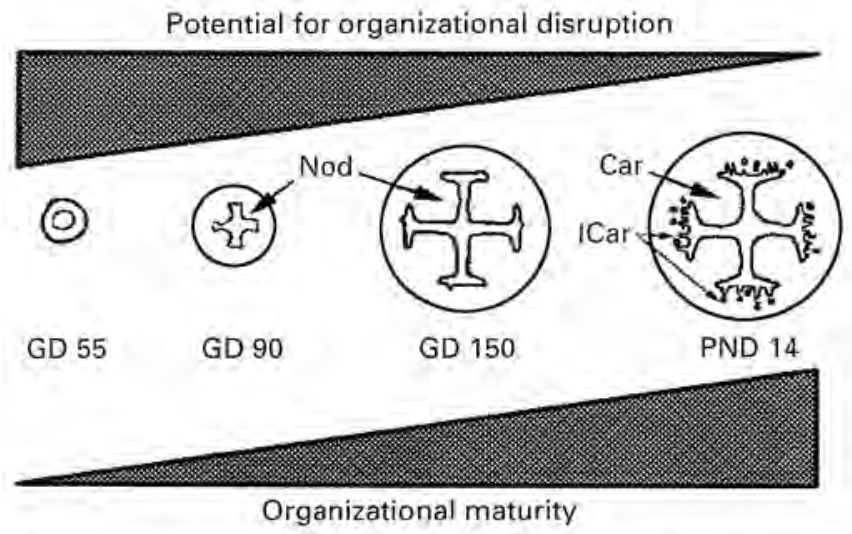

Fig. 1. Schematic representation of ovine uterine morphogenesis between gestational day (GD) 55 and postnatal day 14 (PND 14; birth = PND 0). Significant caruncular morphogenesis occurs prenatally (GD $150=$ term), while genesis and proliferation of endometrial glands (adenogenesis) is a postnatal event in both sheep and cattle (Nod: precaruncular nodule; Car: caruncle; ICar: intercaruncular area). In general, the potential for organizational disruption of uterine development is inversely related to tissue maturity.

for identification of critical, steroid-sensitive developmental periods, and a scheme for the creation of extreme adult uterine phenotypes (lesion models) of use in studies of uterine function. The objectives of this review are to: (1) summarize primary developmental events that support uterine organization; (2) present evidence that the functional integrity of adult uterine tissues is determined, in part, by the success of steroid-sensitive postnatal uterine organizational events; (3) describe strategies for creation of extreme adult uterine phenotypes in domestic ruminants, based on the concept of endocrine disruption; and (4) present evidence of the utility of such models for study of uterine development and function. Where possible, emphasis will be placed on uterine development in sheep and cows.

\section{Uterine Organogenesis}

The uterus develops as a specialization of the paramesonephric ducts, which give rise to the infundibula, oviducts, uterus, cervix and anterior vagina (Bartol, 1999). Paramesonephric fusion occurs between gestational day (GD) 34 and 55 in sheep (Wiley et at., 1987), and GD 55 and 60 in cattle (Marion and Gier, 1971). Fusion is partial in both species, producing a bicornuate uterus that supports intercornual migration of embryos.

Uterine histogenesis has been described to some extent for both cattle (see Marion and Gier, 1971; Atkinson et al., 1984; and references therein) and sheep (Wiley et al., 1987; Bartol et al., 1988a,b). Differentiation of paramesonephric tissues into histologically discernible zones indicating endometrium and presumptive myometrium is evident in the ovine fetus by GD 55, and in the bovine fetus by GD 70. Definitive uterine tissue layers, including the adluminal zone of densely packed endometrial stroma or stratum compactum, the deeper more loosely arranged stromal cells of the stratum spongiosum, and both inner and outer layers of myometrial smooth muscle, are evident in sheep and cattle by GD 90-100. Caruncles, raised aglandular structures that are macroscopic features of the adult endometrium in sheep and cattle, emerge during fetal life as precaruncular nodules (Fig. 1). Extensive prenatal caruncular morphogenesis defines both the number and distribution of these structures along the uterine wall. Genesis of uterine glands 
(adenogenesis) begins during the last month of gestation when short epithelial invaginations appear along the uterine mucosa surrounding the base of precaruncular nodules. Endometrial morphogenesis is completed postnatally with continued growth of caruncles, extensive proliferation of endometrial glands, and establishment of definitive aglandular caruncular and intensely glandular intercaruncular endometrial areas.

\section{Organizational Mechanisms}

Mechanisms regulating growth and differentiation of the paramesonephric duct axis in ruminants are not well defined. Presently, much is inferred about these mechanisms from studies of laboratory species. Jost (1953) established the paradigm that prenatal urogenital tract development in female mammals is an ovary-independent process. Uterine development is also unaffected for defined periods after ovariectomy at birth in the mouse (Bigsby and Cunha, 1985), rat (Branham and Sheehan, 1995), pig (Tarleton et al., 1998) and sheep (Bartol et al, 1988a,b). Thus, uterine organizational mechanisms are ovary-independent and may be steroid-independent for some period before and after birth.

\section{Roles for ligand-dependent nuclear receptors}

The extent to which members of the nuclear receptor superfamily of ligand-regulatable transcription factors are required to support uterine development during pre- and early postnatal life is unclear. However, female mice lacking functional oestrogen receptor- $\alpha$ (ER) or progesterone receptor (PR) genes were born with complete reproductive tracts, indicating that uterine organogenesis, at least in the mouse, does not require ER, PR or their cognate ligands (Korach et al., 1996; Lydon et al., 1996). Uterine hypoplasia in ER-null mice confirmed that an active ER system is required for uterine growth (Korach et al., 1996). Uterine hypoplasia was also observed in weaned mice lacking receptors for 1 $\alpha, 25$-dihydroxy vitamin D3 (Yoshizawa et al., 1997). In addition, the fact that retinyl palmitate administered to neonatal pigs perturbed early postnatal uterine development (Vallet et al., 1995), and that retinoids can affect homeogene expression (see below, and Marshall et al., 1996), indicates that retinoic acid receptors may mediate uterine organizational events.

Ontogeny of steroid receptor expression and function in developing ungulate uterine tissues are incompletely characterized. In the cow, PR mRNA was not detected consistently in dispersed fetal uterine cells from mid- to late gestation, whereas ER mRNA was detected on GD 100-110 and increased on GD 185-200 (Malayer and Woods, 1998). Oestrogen did not bind to or affect DNA synthesis in cultured bovine mesonephric cells obtained on GD 50-59 (Winters et al., 1993). However, oestrogen responsiveness was reported for cultured uterine cells from GD 185-200 (Malayer and Woods, 1998). Thus, neither PR nor functional ER may be present in developing uterine tissues prenatally until after gross uterine morphology and basic histoarchitectural features of the uterine wall have emerged (see above). Since exposure of the immature urogenital tract to steroids can affect the integrity of adult tissues (see below), and steroids are present in the fetal circulation throughout gestation, ontogeny of steroid sensitivity in developing uterine tissues may reflect a natural strategy to ensure organizational success.

Expression of functional steroid receptors during the perinatal period may be necessary for normal uterine development (Bartol et al., 1988b; Malayer and Woods, 1998; Tarleton et al., 1998): Nuclear steroid receptors mediate classical ligand-dependent events and enhance target cell responsiveness to peptide growth factors by coupling with membrane receptor-mediated signal transduction pathways (Smith, 1998). Thus, expression of ER-positive (ER+) character in uterine cells later in development, as described for cows (Malayer and Woods, 1998), may define the point at which oestrogens begin to elicit trophic effects on the fetal uterus and(or) increase the sensitivity of $\mathrm{ER}+$ uterine target cells to paracrine mediators of oestrogen action such as insulin-like growth factor I (IGF-I) or epidermal growth factor (EGF). Like the ER-null mouse (Korach et al., 1996), both IGF-Inull and EGF receptor (EGFR)-null mice have hypoplastic uteri (Baker et al., 1996; Hom et al., 1998). 
Uterotrophic effects of oestradiol were limited to epithelium and virtually absent from fibromuscular stroma when EGFR expression, also documented in the fetal bovine uterus (Malayer and Woods, 1998), was eliminated in mice (Hom et al., 1998). Thus, compartment-specific cross-talk between growth factor and steroid receptor signalling pathways may affect uterine growth in the fetus and neonate.

\section{Homeogenes as effectors of uterine organization and tissue stability}

Homeogenes are primary effectors of tissue organization. Mammalian homeogenes encode transcription factors that determine regional tissue identities along anteroposterior body axes, and may maintain functional stability of adult tissues (Taylor et al., 1997). Expression of homeogenes Hoxa-9, $-10,-11,-13$ and Msx1 is uniform along the murine paramesonephric duct prenatally, but becomes restricted spatially during the first two weeks of postnatal life such that oviducts express Hoxa-9, the uterus Hoxa-10,-11 and Ms $x 1$, the cervix Hoxa-11 and -13 , and the anterior vagina Hoxa13. This pattern persists in adult murine and human genital tracts and may be subject to steroid regulation (Pavlova et al., 1994; Taylor et al., 1997).

Disruption of homeogene expression is associated with homeotic tissue transformations. In adult ewes, prolonged exposure to oestrogen causes permanent infertility associated with destabilized cervical histoarchitecture and redifferentiation of the cervix toward a more anterior, uterine-like phenotype (Adams and Sanders, 1993; Adams, 1995). This partial homeotic transformation can be accompanied by development of uterine glandular cysts and adenomyotic lesions (Adams, 1995). Similarly, uteri of mice lacking functional Hoxa-10 (Benson et al., 1996) or Hoxa-11 genes (Gendron et al., 1997) displayed partial homeotic transformation toward a more anterior, oviduct-like phenotype. Impaired ability to form uterine glands was observed in Hoxa-11 mutants (Gendron et al., 1997). Mice lacking functional Hoxa-10, Hoxa-11 or Hmx3 genes cannot support embryo development due to aberrant expression of critical uterine proteins (Gendron et al., 1997; Wang et al., 1998). Uterine expression of Wnt-5a was altered in Hmx3-null mice (Wang et al., 1998). Stromal expression of Wnt-5a affects uterine epithelial expression of Msx1, which may be important for maintenance of epithelial receptivity to stromal and conceptus signals (Pavlova et al., 1994). Thus, structural and functional stability of uterine tissues may evolve and be maintained through steroidsensitive mechanisms operating to ensure spatially unique, tissue-specific patterns of homeotic gene expression yet to be defined in domestic ruminants.

\section{Cell-cell and cell-matrix interactions and selective stabilization}

Uterine development requires continuous reciprocal interactions between epithelium and underlying stroma (Bigsby, 1991). The communication network that develops through these interactions involves paracrine-acting factors and their receptors that may include homeogene products and Wnts (see above, and Moon et al. 1997,), hepatocyte growth factor (HGF; Sugawara et al,, 1997), EGF (Hom et al., 1998), heparin-binding EGF (HB-EGF; Zhang et al., 1998), transforming growth factors (TGF; Takahashi et al., 1994; Godkin and Dore, 1998), IGF (Stevenson et al., 1994), keratinocyte growth factor (KGF; Koji et al., 1994), vascular endothelial growth factor (VEGF; Grant et al., 1995; Torry and Torry, 1997), and others. Specific regulatory interactions that must evolve for successful uterine development reflect communication between epithelial, stromal and endothelial cells within the context of their extracellular matrix (ECM; Ettinger and Doljanski, 1992; Grant et al, 1995). These relationships direct local patterns of gene expression and dictate cellular responsiveness to gene products (Ettinger and Doljanski, 1992). Therefore, the ideal uterine organizational programme may be determined epigenetically through selective stabilization of specific cell-cell and cell-ECM interactions. This organizational model predicts that each configuration of cells and ECM during the course of development increases the likelihood of the next, and decreases the likelihood of others that might be less desirable (Ettinger and Doljanski, 1992). Conversely, aberrations in initial conditions would be amplified through development with severe implications for end-organ integrity. If applicable to domestic ruminants, this model predicts 


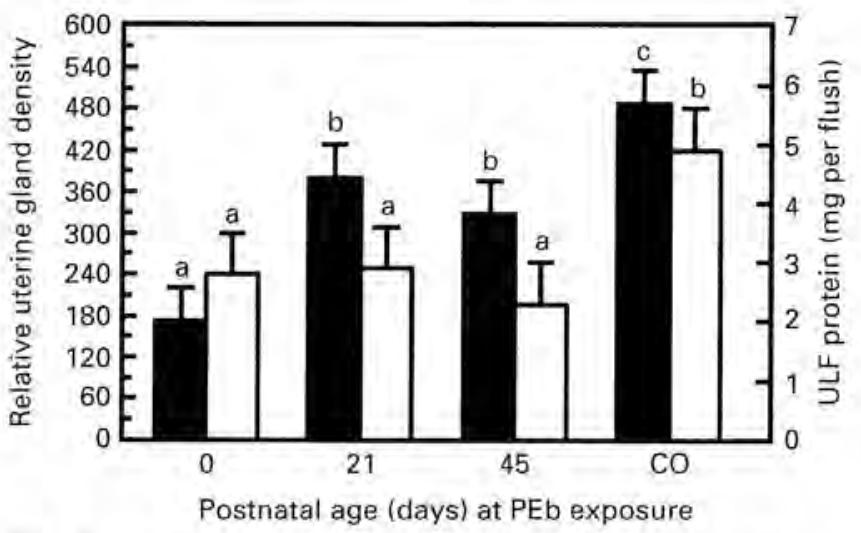

Fig. 2. Effects of chronic (about 200 days) administration of progesterone plus oestradiol benzoate $(\mathrm{PEb})$, beginning on either postnatal day 0 (PND $0=$ birth), 21 or 45 , on relative endometrial gland density (dark bars) and uterine luminal fluid (ULF) protein content (open bars) in adult beef heifers during dioestrus. Treated heifers ( $n=5$ per group) received a single implant containing progesterone $(100 \mathrm{mg})$ and oestradiol benzoate $(10 \mathrm{mg})$. Control (CO) heifers were not exposed to progesterone and oestradiol benzoate. Uteri were obtained from heifers at approximately 15 months of age on day 12 of a $\mathrm{PGF}_{2 a}$-induced oestrous cycle. For each response, bars with different letters are significantly different $(P<0.01)$. (Adapted from Bartol et al., 1995.)

that disruption of critical primary conditions that define the programmatic context for uterine development should alter the capacity of uterine tissues to develop and function properly.

\section{Postnatal Disruption of Uterine Development}

The idea that disruption of development during specific 'critical' periods could have enduring effects on adult tissues is not new. Perinatal exposure of rodents to steroids, including oestrogens progestins and androgens, can disrupt uterine development, initiate uterine lesions and impair fertility (Sananes et al., 1980; Mori and Nagasawa, 1988; Ohta, 1995). Tissue susceptibility to such organizational effects of steroids tends to be inversely related to age or tissue maturity and directly related to dosage and duration of exposure (Fig. 1).

Postnatal exposure to steroids can have lasting effects in domestic ungulates (Bartol et al., 1993, 1995; Spencer et al., 1993; King et al., 1995). Moreover, the potential for inappropriate exposure of developing tissues in domestic animals to either natural hormones or xenobiotics is real. Exposure can occur: (1) physiologically, as a consequence of aberrant production of hormones during critical periods; (2) by diet, as a consequence of the consumption of bioactive agents such as phytoestrogens or mycotoxins (Adams, 1995); (3) pharmacologically, as a consequence of the intentional use of endocrinologically active agents to enhance performance traits (Hancock et al., 1994; King et al., 1995); and (4) unintentionally, as a consequence of the presence of endocrine-active industrial pollutants in the environment (Cooper and Kavlock, 1997). Compounds that disrupt development by altering critical endocrinological events are categorized as endocrine disruptors (EDs).

\section{Postnatal exposure to steroidal endocrine disruptors in cows}

Commercially, beef calves are often exposed to steroidal agents released from implants designed to enhance growth performance. In the United States, implants approved for female calves intended 
for use as breeding replacements contain either the oestrogenic compound zeranol alone ( $36 \mathrm{mg}$ ) (Schering-Plough Animal Health Corp., Union, NJ), or a combination of progesterone (100 mg) and oestradiol benzoate (10 mg) (Fort Dodge Animal Health, KS; Vetlife, Norcross, GA).

Effects of postnatal exposure to zeranol on bovine reproductive performance were related to both period of exposure and dosage. In numerous trials, pregnancy rates decreased by an average of $35 \%$ in yearling heifers given single zeranol implants at birth, but were essentially unaffected by the same treatment initiated between one and 14 months of age, suggesting a critical period for oestrogen sensitivity during the first postnatal month. However, pregnancy rates were depressed by as much as $40 \%$ in heifers treated with two or more zeranol implants between one and 11 months of age (Hancock et al, 1994; Bartol and Floyd, 1996). Chronic exposure to zeranol for 300 days from birth delayed puberty and reduced pre- and postpubertal uterine diameter in beef heifers (King et al., 1995). Similarly, exposure of heifers to several compounds for one year from PND 84, including trenbolone acetate, oestradiol, zeranol, or a combination of TBA and oestradiol, had variable but consistently negative effects on adult uterine wet weights (Moran el al., 1990). These antiuterotrophic effects could reflect lesions of the central nervous system, altered gonadotrophin secretion and lack of uterotrophic support from the ovary. However, abortion frequency increased between GD 25 and 45 in heifers exposed to zeranol from birth to PND 300, indicating that zeranolinduced uterine lesions that affected attachment of the conceptus.

Treatment of beef heifers with an implant designed to release both progesterone and oestradiol benzoate for approximately 200 days beginning on either PND 0, 21 or 45 reduced adult uterocervical wet weight by $35 \%$, myometrial area by $23 \%$, and endometrial area by $27 \%$, regardless of age at first exposure to progesterone and oestradiol benzoate (Bartol et al., 1995). Effects were accompanied by a marked decrease in uterine glandularity that was most severe when exposure began at birth (Fig. 2). Uterine luminal fluid protein content was reduced by approximately $45 \%$ in heifers exposed to progesterone and oestradiol benzoate (Fig. 2). Thus, generalized uterine hypoplasia, endometrial aplasia and altered uterine protein content were observed in cyclic adult heifers 13.5 to 15 months after initiation of chronic (about 200 day) exposure to progesterone and oestradiol benzoate on or before PND 45 , and a potentially critical period of uterine sensitivity to developmental disruption induced by progesterone and oestradiol benzoate was identified between birth and PND 21 (Bartol et al., 1995).

Subsequently, crossbred beef heifers were assigned to one of five groups at birth (groups I-V; $n=$ 5 or 6 heifers per group). Heifers in groups I-III received a single progesterone and oestradiol benzoate implant at birth, while those in groups IV and V served as unexposed controls (CO). All heifers were laparotomized on PND 21, when each uterus was measured and progesterone and oestradiol benzoate implants were removed from calves in group I. This created a group of uterineintact adults exposed to progesterone and oestradiol benzoate for 21 days from birth. In addition, on PND 21, heifers in groups II (progesterone and oestradiol benzoate) and V (CO) were hemihysterectomized to permit evaluation of short-term treatment effects on uterine histoarchitecture. Jugular blood samples were taken from heifers at 16 months of age during dioestrus, before and aftex administration of oxytocin (100 iu), and plasma was assayed for 13,14-dihydro-15ketoPGF $_{2 e}(\mathrm{PGFM})$ as a reflection of oxytocin-inducible uterine prostaglandin generating ability (Wolfenson et al., 1993). Uteri were obtained at slaughter during dioestrus at 26 months of age. Tissues were processed for histomorphometry, and endometrial samples were assayed for oxytocin receptor concentrations (Spencer et al., 1995; F. F. Bartol and M. A. Mirando, unpublished).

Anti-uterotrophic effects of progesterone and oestradiol benzoate were evident by PND 21, when both uterine horn length (141.6 versus $78.2 \pm 5.0 \mathrm{~mm}$ ) and volume (5019 versus $2020 \pm 59 \mathrm{~mm}^{3}$ ) were reduced $(P<0.05)$ in treated heifers. Nascent uterine glands were present in both groups on PND 21, but were more frequently branched and appeared less stable structurally in heifers exposed to progesterone and oestradiol benzoate (Fig. 3). Chronic exposure to progesterone and oestradiol benzoate, exceeding 21 days from birth, was required to produce overt effects on adult bovine uterine size and endometrial histoarchitecture. Uterine weights (Fig. 4a) indicated that antiuterotrophic effects of chronic exposure to progesterone and oestradiol benzoate alone (group III) were approximately equivalent to neonatal hhx (group V). Effects of hhx combined with chronic 

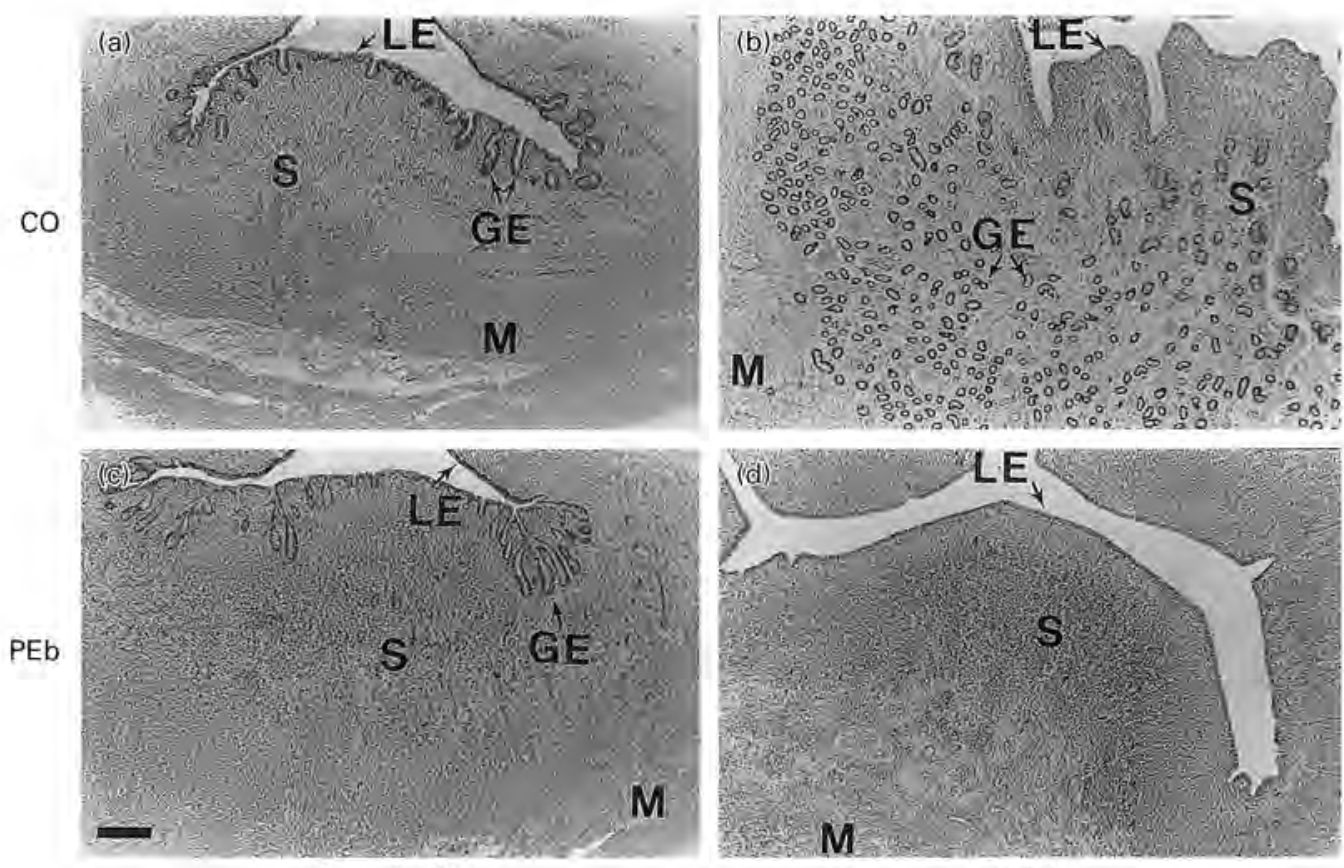

Neonate D21

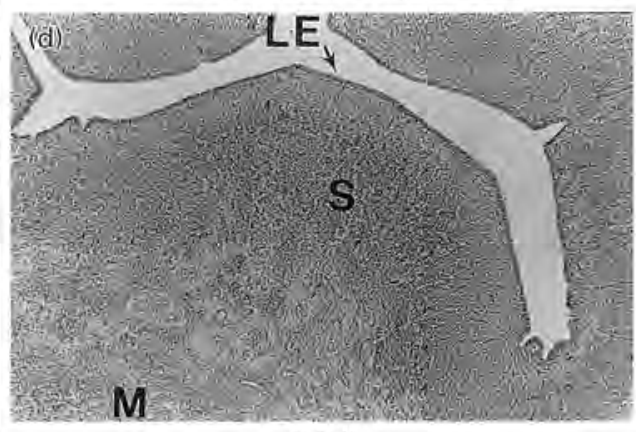

Adult

Fig. 3. Postnatal histogenesis of the bovine uterine wall and extreme effects of exposure to progesterone plus oestradiol benzoate $(\mathrm{PEb})$ from birth on adult uterine histoarchitecture. Photomicrographs show histology of the uterine wall in individual animals hemihysterectomized on neonatal day 21 (a and c), and in the contralateral uterine horn of the same animals at 26 months of age during dioestrus (b and d). Micrographs (a) and (b) illustrate normal histogenesis in a representative control heifer (CO) not exposed to progesterone and oestradiol benzoate. Micrographs (c) and (d) illustrate an extreme consequence of chronic exposure to progesterone and oestradiol benzoate from birth in an adult heifer. Nascent endometrial glands (GE) were present in both $\mathrm{CO}$ and heifers exposed to progesterone plus oestradiol benzoate on PND 21 (a versus c). Chronic exposure to progesterone plus oestradiol benzoate reduced or eliminated endometrial glands in adults (b versus d). No endometrial glands were found in multiple serial sections of the adult uterus (d) that was exposed neonatally to progesterone plus oestradiol benzoate. However, this neonatally hemihysterectomized heifer displayed oestrous cycles of normal duration. LE: luminal epithelium, GE: glandular epithelium; S: endometrial stroma; M: myometrium. Haematoxylin and eosin staining. Scale bar represents $300 \mu \mathrm{m}$.

progesterone and oestradiol benzoate were additive, producing a $52 \%$ reduction in uterine mass in group II heifers (Fig. 4a). The reduction in adult endometrial glandularity, expected with chronic exposure to progesterone and oestradiol benzoate, was most severe for group II heifers, in which few or no endometrial glands were found (Fig. 3). Consistently, both peak uterine PGFM response and endometrial OTR concentrations were reduced $(P<0.07)$ in group II heifers (Fig. 4).

Treatment-induced loss of oxytocin-sensitive prostaglandin-generating uterine parenchyma may explain the reduced peak PGFM response observed in group II heifers (Fig. 4). However, all heifers displayed regular oestrous cycles of normal duration, including the group II heifer in which no endometrial glands were found (Fig. 3). Thus, uterine glandular epithelium may not be essential for normal cyclicity in cattle. Results also indicate that evidence of normal cyclicity is not necessarily evidence of normal endometrial integrity.

Results show that transient postnatal exposure to steroids can have specific, extreme and lasting effects on the adult bovine endometrium that could alter the embryotrophic potential of the uterine environment (Martal et al., 1997). Effects reflect particular conditions of exposure and tend to be 

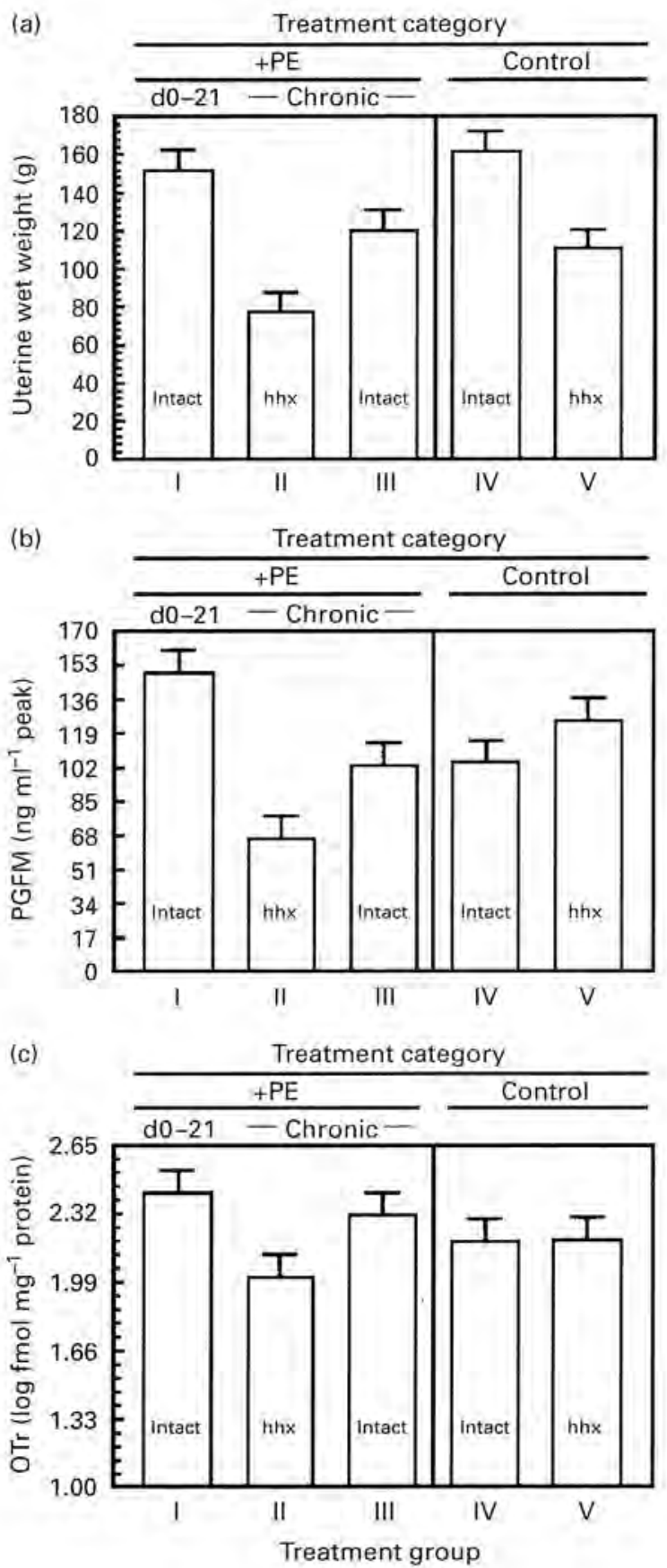

Fig. 4. Effects of neonatal exposure to progesterone plus oestradiol benzoate (PEb) from birth to neonatal day 21 (d0-21), or for approximately 200 days from birth (chronic), and hemihysterectomy (hhx) on neonatal day 21, on specific uterine responses in adult beef heifers $(n=5-6$ per treatment group). Responses (least squares means + SEM) illustrated are: (a) uterine wet weight; (b) peak peripheral plasma concentrations of 13,14-dihydro-15-keto $\mathrm{PGF}_{2 a}$ (PGFM) in response to an oxytocin (100 iu) challenge during dioestrus; and (c) endometrial oxytocin receptor density (OTr). Uterine weight (a) was reduced by neonatal progesterone plus oestradiol benzoate 
more pronounced when initiated at birth. Studies also showed that postnatal exposure to steroidal endocrine disruptors of uterine development could be used to create unique adult uterine phenotypes.

\section{Exposure to progestin from birth and uterine development in sheep.}

Endometrial glands proliferate rapidly between PND 0 and 26 in the ewe (Bartol et al., 1988a,b).

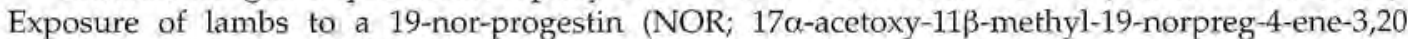
dione) from PND 0 to 13 prevented gland development, as reflected by their absence in tissues from PND 13 (Bartol et al., 1988a). Withdrawal of the progestin block permitted genesis of poorly organized uterine glands between PND 13 and 26 (Fig. 5A). Similarly, patterns of in vitro uterine protein synthesis characteristic of tissues obtained from NOR-exposed ewes on PND 13 and from NOR-withdrawn ewes on PND 26 were not identical to those observed during the normal morphogenetic transition between PND 0 and PND 13 (Fig. 5b). It was proposed that: (1) withdrawal of uterine tissues from a progestin-dominated prenatal environment at birth provides an endocrine cue for initiation of uterine adenogenesis; (2) this organizational programme could be disrupted by postnatal exposure to NOR; and that (3) prolonged exposure to NOR from birth should disintegrate critical organizational events sufficiently to produce a stable, extreme endometrial phenotype in adult ewes characterized by the absence of uterine glands, an organizationally induced uterine gland 'knock-out' (UGKO).

The 'UGKO' phenotype was created in adult ewes exposed to NOR for 32 weeks from birth (Bartol et al., 1997). Uteri were obtained from NOR-exposed UGKO ewes during follicular $(n=5)$ and luteal $(n=2)$ phases of the ovarian cycle, and from one ewe with inactive ovaries. In striking contrast to intensely glandular endometrium obtained from control ewes during dioestrus (Fig. 6), endometrium from UGKO ewes was aglandular (7/8), or contained a few glandular cysts $(1 / 8$, not shown). This extreme phenotype may be induced by transient exposure to NOR for no more than 8 weeks from birth (T. E. Spencer, T. L. Ott, F. W. Bazer and F. F. Bartol, unpublished). Studies to determine whether UGKO ewes can cycle normally and conceive, and whether pregnancy can be established and maintained in an aglandular uterus are underway.

Distinct patterns of endometrial gene expression were identified between control and UGKO endometrium using mRNA differential display PCR. The majority $(>95 \%)$ of over 80 cDNAs cloned to date were amplified from control and absent from UGKO samples (Fig. 7). If structural differences between UGKO and control tissues are reflected at the transcriptional level, many differentially expressed mRNAs should be specific to the epithelium. Consistently, an antisense cRNA probe generated from endometrial cDNA DD54, identified as described above, hybridized specifically to uterine luminal and glandular epithelium from normal cyclic and pregnant ewes (Fig. 8a). Northem blot analysis revealed two major endometrial transcripts of approximately $2 \mathrm{~kb}$ and $6 \mathrm{~kb}$, and DD54 expression increased during dioestrus, suggesting endocrine regulation of this epithelial gene product (Fig. $8 \mathrm{~b}$ and unpublished results). The DD54 cDNA lacks sequence homology with known genes as determined using the BLAST algorithm (National Center for Biotechnology Information, NIH, Bethesda, MD). Results illustrate the immediate utility of the UGKO model for discovery of potentially novel genes encoding uterine proteins required for establishment of an embryotrophic uterine microenvironment in domestic ungulates (Martal et al., 1997).

exposure $(+\mathrm{PE}<$ Control, $P<0.06)$ and hhx $(P<0.01)$. Among groups exposed to progesterone plus oestradiol benzoate (I-III), uterine weight was lower in group II than in groups I and III $(P<0.01)$. Relative to intact controls (group IV), short-term exposure to progesterone plus oestradiol benzoate (d0-21, group I) did not affect uterine weight. Peak PGFM concentrations (b), defined as the maximum value detected for each heifer within 45 min after oxytocin, were not affected by progesterone plus oestradiol benzoate exposure or hhx alone. However, among progesterone plus oestradiol benzoate exposed heifers, peak PGFM values were lower $(P<0.07)$ in group II than in group III. Identical relationships were detected for endometrial OTR density (c). 
(a)
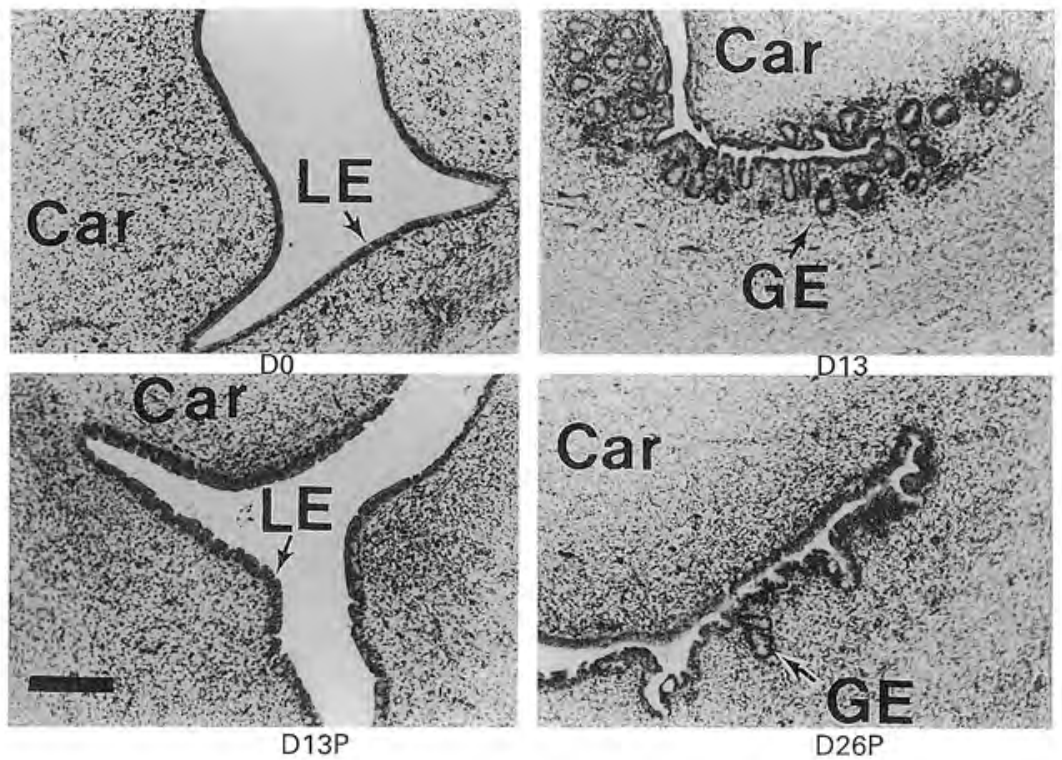

(b)
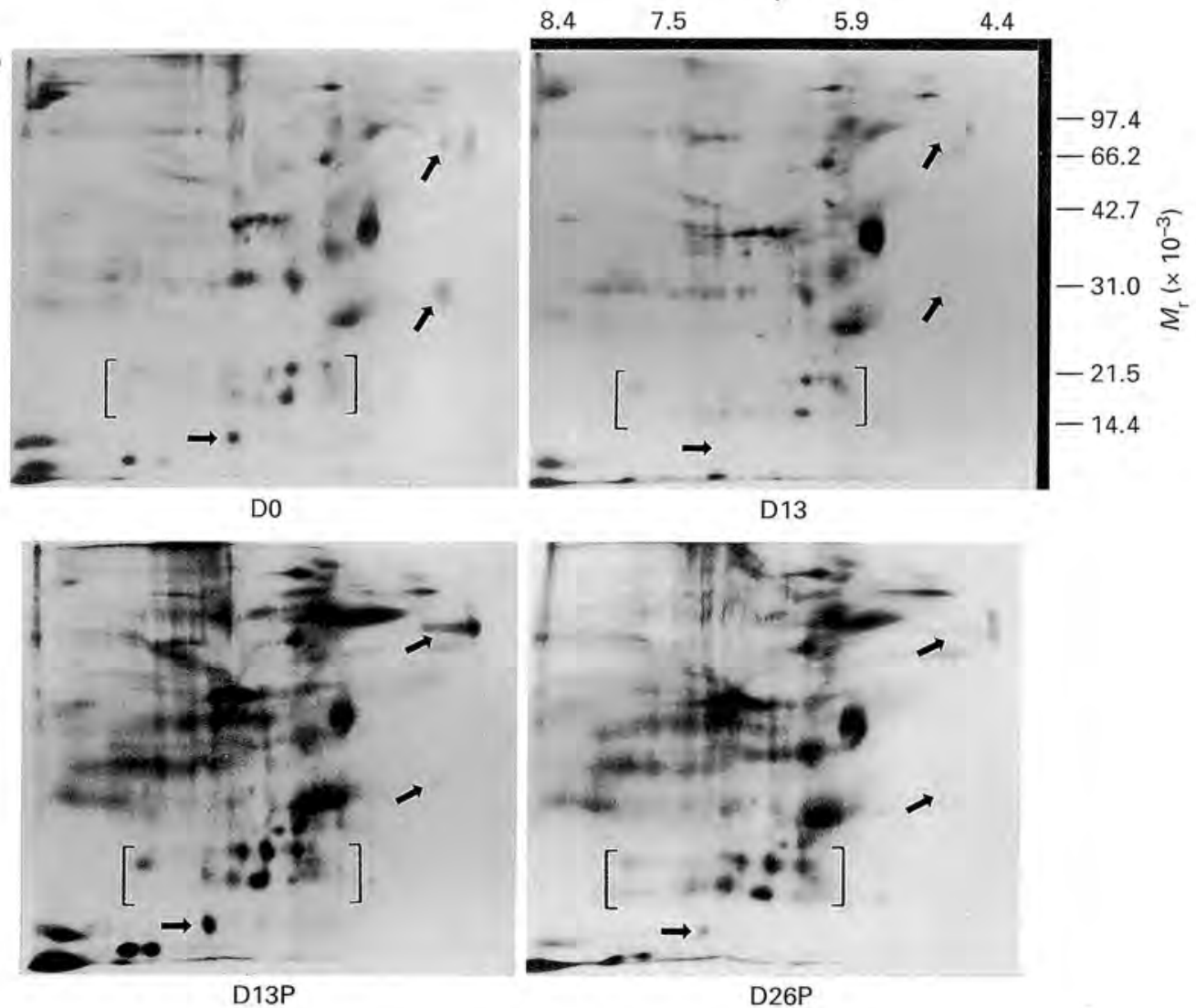

Fig. 5. For legend see facing page. 


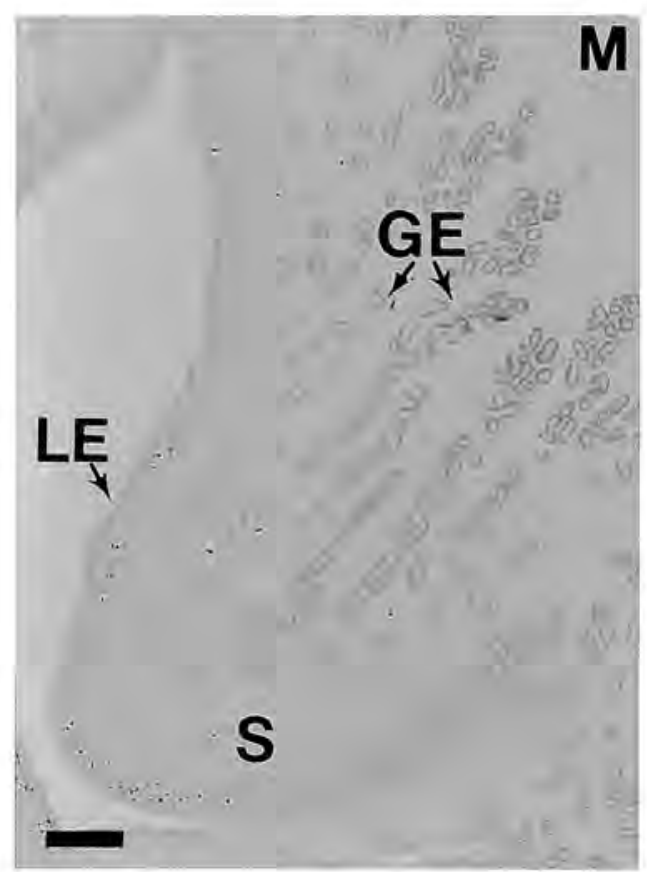

Control

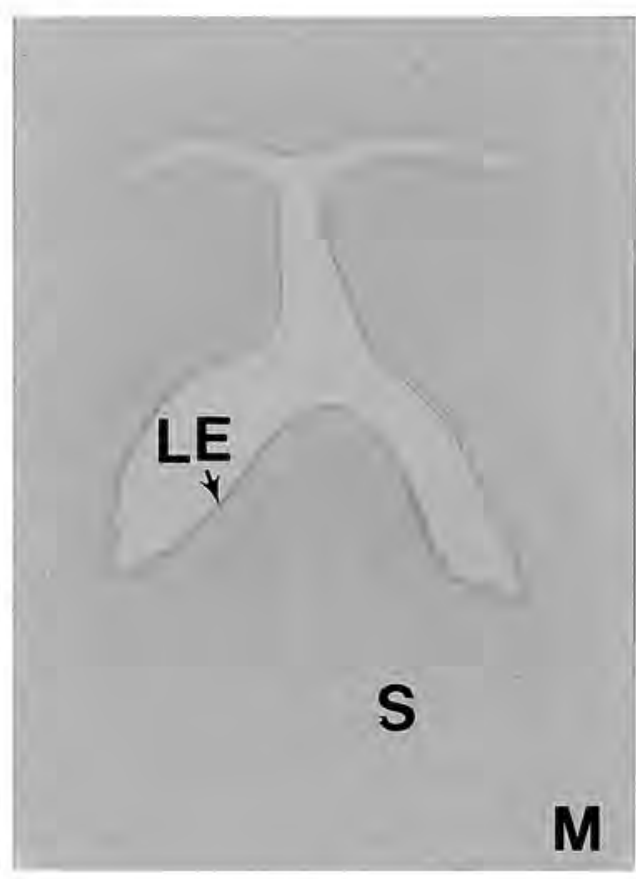

UGKO

Fig. 6. Histological characterization of the uterine gland 'knock-out' (UGKO) phenotype in adult ewes. Photomicrographs depict normal adult endometrial histology for a typical control ewe, and the UGKO phenotype in an adult ewe that was exposed to a 19-norprogestin (19-norpreg-4-ene-3,20 dione) for 32 weeks from birth. Note the intense endometrial glandularity characteristic of control endometrium (left), compared with the glandless condition found in the UGKO endometrium (right). Tissues were obtained during dioestrus. LE: luminal epithelium; GE: glandular epithelium; S: endometrial stroma; M: myometrium. Scale bar represents $33 \mu \mathrm{m}$.

Fig. 5. Effects of chronic neonatal exposure of ewe lambs to 19-norprogestin ( $\mathrm{P} ;$ 19-norpreg-4-ene-3,20 dione) from birth on: (a) postnatal histogenesis of the endometrium (Car: caruncle; LE: luminal epithelium; GE: glandular epithelium); and (b) patterns of uterine protein synthesis in vitro in neonatal ewes ovariectomized at birth. (a) Endometrial glands are absent at birth (D0), but present throughout the intercaruncular endometrium by postnatal day (PND) 13 (D13). When ewe lambs are exposed to progestin from birth to PND 13, endometrial adenogenesis is inhibited and uterine glands are absent on PND 13 (D13P). Withdrawal of the progestin block on PND 13 permits some gland development as observed on PND 26 (D26P), although newly formed endometrial glands are structurally abnormal (D26P versus D13). (b) Uterine tissues of the type illustrated in (a) were explanted under defined conditions in the presence of $\mathrm{L}-4,5-\left[{ }^{3} \mathrm{H}\right]$ leucine and labelled proteins in explant medium were identified by fluorography of dried two-dimensional PAGE gels. Labelled uterine products were separated by isoelectric focussing in the first dimension $(\mathrm{pH})$ and SDS-PAGE in the second $\left(M_{\mathrm{r}} \times 10^{-3}\right)$. Changes in patterns of uterine protein synthesis associated with uterine development between birth (D0) and PND 13 (D13) are illustrated by the top fluorographs. Some proteins produced by normally glandless uterine tissues from postnatal day 0 are no longer produced, or produced in the same relative abundance by tissues from postnatal day 13, in which endometrial glands are normally present (D0 versus D13, arrows). Chronic exposure of ewe lambs to progestin from birth inhibits gland genesis, restores production of some uterine proteins and induces production of others (D0 versus D13P, arrows and brackets). Tissues obtained on PND 26 after withdrawal of the progestin block to adenogenesis on PND 13 (D26P) displayed suppressed production of some proteins normally associated with uterine gland development (arrows), but relatively stable production of other proteins induced by progestin exposure (brackets). Scale bar represents $200 \mathrm{~mm}$. 


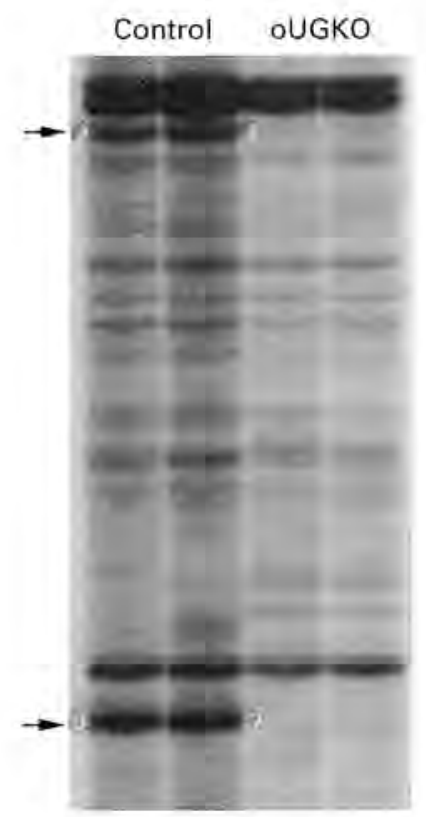

Fig. 7. Progestin-induced inhibition of uterine gland genesis alters transcriptional activity in adult ovine endometrium. An autoradiograph of [32P- $\alpha$ ]ATP-labelled cDNAs generated by mRNA differential display PCR (DD-PCR) and separated by electrophoresis on a $4.5 \%$ acrylamide-urea sequencing gel is shown. Typical results from duplicate endometrial total RNA samples obtained from normal control (left lanes) and uterine gland 'knock-out' (UGKO; right lanes) endometrium are shown (see Fig. 6). Evidence of differential gene expression is illustrated by the presence of bands in control lanes (arrows) and the absence of these bands in UGKO lanes.

Fig. 8. Expression of endometrial DD54 mRNA. (a) Representative dark-field photomicrographs of DD54 mRNA expression in endometrium obtained from cyclic and pregnant ewes detected by in situ hybridization analysis. The cDNA corresponding to DD54 was identified by mRNA DD-PCR as in Fig. 7. Cross-sections of uteri from cyclic and pregnant ewes were hybridized with [55]UTP-labelled sense and antisense DD54 CRNA probes and hybridization signals visualized by autoradiography. Tissues shown are from a cyclic ewe on day 1 after oestrus (D1C), and a pregnant ewe on day 19 (D19Px). Note intense hybridization signal in luminal epithelium (LE) and glandular epithelium (GE). No signal above background was detected with the labelled sense probe (D1C Sense). (b) Expression of endometrial DD54 mRNA detected by northern hybridization analysis. Two DD54 mRNA transcripts of approximately $2 \mathrm{~kb}$ and $6 \mathrm{~kb}$ (arrows) were identified in endometrial total RNA ( $20 \mathrm{mg}$ ) from cyclic (days 1, 5, 9 and 15 after oestrus) and pregnant ewes ( $\mathrm{Px}$; days 15 and 19) with a radiolabelled antisense cRNA probe generated from DD54 cDNA template. Expression of this epithelial gene product increased during dioestrus. Scale bar represents $40 \mu \mathrm{m}$. 
(a)
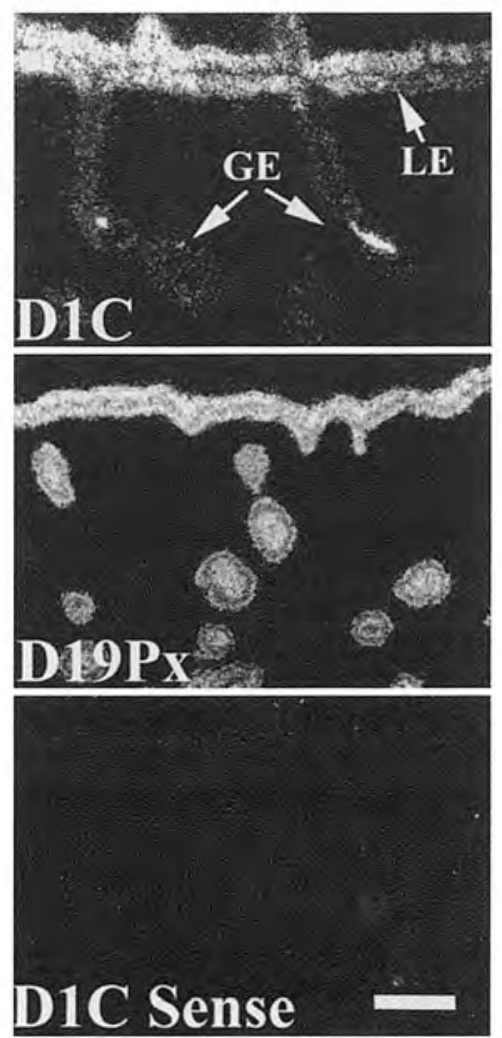

(b)
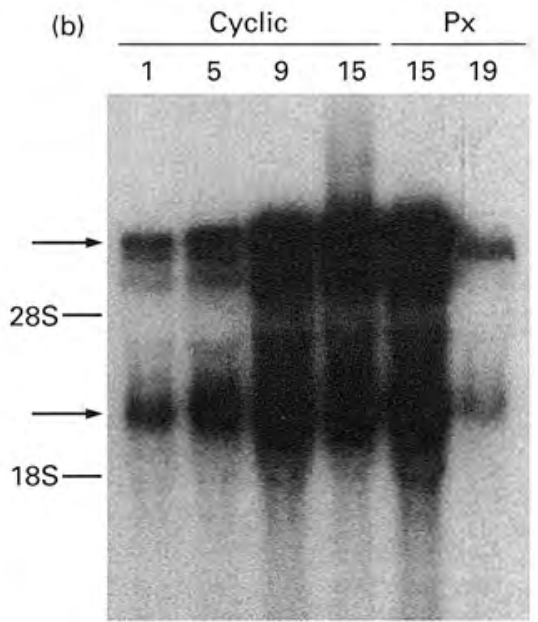

Fig. 8. For legend see facing page. 


\section{Conclusions}

The extent to which embryo mortality (Martal et al, 1997) or uteroplacental dysfunctions associated with fetal growth retardation in domestic ruminants are attributable to uterine lesions induced by disruption of development is unknown. However, the fact that such lesions can be induced indicates that reproductive performance could be affected in this way. Since, in both cattle and sheep, postnatal uterine organizational events are steroid sensitive, mechanisms regulating these events are likely to involve steroid receptors and their co-activators and co-repressors (Hirotaka et al., 1997). How the ideal uterine organizational programme evolves, and the extent to which disruption of organizationally critical cell-cell and cell-matrix interactions may affect the fate of uterine tissues and cells are topics that warrant investigation if factors affecting uterine capacity to support reproduction in domestic ruminants are to be defined.

Studies in cows and ewes indicate that normal and aberrant programmes of uterine organization, and consequences of organizational disruption, can be delineated by comparing patterns of uterine development and function in neonatally steroid exposed and unexposed animals. Physiological, biochemical and molecular comparisons of normal and lesioned adult uterine tissues should enable identification of factors affecting uterine function, developmental determinants of uterine integrity, biological markers of exposure to steroidal disruptors of uterine development, and rapid identification of novel uterine genes. Such studies will facilitate the design of environments and refinement of management guidelines to ensure that genetic potential for reproductive performance is realised, and will aid in efforts to evaluate the potential reproductive impact of environmental exposure to endocrine disruptors during development.

The authors thank Dr William W. Thatcher (University of Florida) and Dr Mark A. Mirando (Washington State University) for performing PGFM and OTR assays; Merial (Athens, GA) for providing Norgestomet implants; Ms Margaret M. Joyce for technical assistance; members of Dr Bazer's laboratory for assistance with surgery and collection of ovine tissues; Dr Shawn W. Ramsey and Mr Todd Taylor of the Texas A \& M University Sheep and Goat Center, and Mr Jason Word for care and management of ewes; and Dr Dale A. Coleman and Ms Mabel Robinson (Auburn University) for technical assistance in bovine and early ovine studies. Special thanks are extended to the Center for Animal Biotechnology, Institute of Biosciences and Technology at Texas A\&M University, for support leading to establishment and initial molecular characterizations of the ovine UGKO model. Work reported here was supported in part by AAES Project ALA 04-022 and USDA-NRI grants 95-37203-1995 to FFB and 98-35203-6322 to TES. This is AAES Journal No. 4-985927.

\section{References}

Adams NR (1995) Organizational and activational effects of phytoestrogens on the reproductive tract of the ewe Proceedings of the Society for Experimental Biology and Medicine $20887-91$

Adams NR and Sanders MR (1993) Development of uterus-like redifferentiation in the cervix of the ewe after exposure to estradiol-17ß Biology of Reproduction 48 357-362

Atkinson BA, King GJ and Amoroso EC (1984) Development of the caruncular and infercaruncular regions in the bovine endometrium Biology of Reproduction 30 763-774

Baker J, Hardy MP, Zhou J, Bondy C, Lupu E, Bellve AR and Efstratiadis A (1996) Effects of an Igf1 gene null mutation on mouse reproduction Molecular Endocrinology $10903-918$

Bartol FF (1999) Uterus: Nonhuman. In Encyclopedia of Reproduction Vol. 4 Eds E Knobil and JD Neill. Academic Press, San Diego, CA

Bartol FF and Floyd JG (1996) Critical periods, steroid exposure and reproduction Proceedings for the Anmual Meeting of the Sociely for Theriogenology 101-111

Bartol FF, Wiley AA, Spencer TE, Vallet JL and Christenson RK
(1993) Early uterine development in pigs Joumal of Reproduction and Fertility Supplement 4899-116

Bartol FF, Johnson LL, Floyd JG, Wiley AA, Spencer TE, Buxton DF and Coleman DA (1995) Neonatal exposure to progesterone and estradiol alters uterine morphology and luminal protein content in adult beef heifers Theriogenology 43 835-844

Bartol FF, Floyd JG, Wiley AA, Coleman DA, Wolfe DF and Thatcher WW (1996) Neonatal steroid exposure and hemihysterectomy affect adult bovine uterine weight and response to oxytocin Btology of Reproduction Supplement 1 54180

Bartol FF, Wiley AA, Spencer TE, Ing NH, Ott TL and Bazer FW (1997) Progestin exposure from birth: epigenetic induction of a unique adult uterine phenotype in sheep - a glandless endometrium Biology of Reproduction Supplement 156133

Bartol FF, Wiley AA, Coleman DA, Wolfe DF and Riddell MG (1988a) Ovine uterine morphogenesis: effects of age and progestin administration and withdrawal on neonatal endometrial development and DNA synthesis joumal of Animal Science 66 3000-3009 
Bartol FE, Wiley AA and Goodlett DR (1988b) Ovine uterine morphogenesis: histochemical aspects of endometrial development in the fetus and neonate Journal of Animal Science $661303-1313$

Benson GV, Lim $\mathrm{H}_{r}$ Paria BC, Satokata I, Dey SK and Maas RL (1996) Mechanisms of reduced fertility in Hoxa-10 mutant mice: uterine homeosis and loss of maternal Hoxa-10 expression Development 122 2687-2696

Bigsby RM (1991) Reciprocal tissue interactions in morphogenesis and hormonal responsiveness of the female reproductive tract. In Cellular Signals Controlling Uterine Eunction pp 11-20 Ed. LA Lavia. Plenum Press, New York

Bigsby RM and Cunha GR (1985) Effects of progestins and glucocorticoids on deoxyribonucleic acid synthesis in the uterus of the neonatal mouse Endocrinology 117 $2520-2526$

Branham WS and Sheehan DM (1995) Ovarian and adrenal contributions to postnatal growth and differentiation of the rat uterus Biology of Reproduction 53 863-872

Cooper RL and Kavlock RJ (1997) Endocrine distuptors and reproductive development: a weight-of-evidence overview Jouinal of Endocrinology 152 159-166

Ettinger L and Doljanski F (1992) On the generation of form by the continuous interactions between cells and their extracellular matrix Biological Reviews 67 459-489

Gendron RL, Paradis H, Hsieh-Li HM, Lee DW, Potter SS and Markoff E (1997) Abnormal uterine stromal and glandular function associated with maternal reproductive defects in Hoxa-11 null mice Biology of Reproduction 56 1097-1105

Godkin JD and Dorè JJE (1998) Transforming growth factor $\beta$ and the endometrium Reviews of Reproduction 3 1-6

Grant DS, Rose RW, Kinsella JK and Kibbey MC (1995) Angiogenesis as a component of epithelial-mesenchymal interactions. In Epithelial-Mesenchymal Interactions in Cancer pp 235-248 Ed ID Goldberg and EM Rosen. Birkhauser Verlag, Basel

Hancock RF, Deutscher GH, Nielsen MK and Colburn DJ (1994) Effects of Synovex C implants on growth rate, pelvic area, reproduction, and calving performance of replacement heifers Journal of Animal Science 72 292-299

Hirotaka S, Spencer TE, Onate SA, Jenster G, Tsai SY, Tsai M-J and O'Malley BW (1997) Role of co-activators and co-repressors in the mechanism of steroid/thyroid receptor action Recent Progress in Formone Research 52 141-165

Hom YK, Young P, Wiesen JF, Miettinen PJ, Derynck R, Werb Z and Cunha GR (1998) Uterine and vaginal organ growth requires epidermal growth factor receptor signaling from stroma Endocrinology 139 913-921

Jost A (1953) Problems of fetal endocrinology: the gonadal and hypophyseal hormones Recent Progress in Hormone Research $8379-418$

King BD, Bo GA, Lulai C, Kirkwood RN, Cohen RDH and Mapletoft RJ (1995) Effect of zeranol implants on age at onset of puberty, fertility and embryo and fetal mortality in beet heifers Canadian Journal of Animal Science 75 225-230

Koji T, Chedid M, Rubin JS, Slayden OD, Csaky KG, Aaronson SA and Brenner RM (1994) Progesterone-dependent expression of keratinocyte growth factor mRNA in stromal cells of the primate endometrium: keratinocyte growth factor as a progestomedin Journal of Cell Biology $125393-401$

Korach KS, Couse JF, Curtis SW, Washburn TR, Lindzey J, Kimbro KS, Eddy EM, Migliaccia S, Snedeker SM, Lubahn DB, Schomberg DW and Smith EP (1996) Estrogen receptor gene disruption: molecular characterization and experimental and clinical phenotypes Recent Progress in Hormone Research 51 159-188

Lydon JP, DeMayo FJ, Conneely OM and O'Malley BW (1996) Reproductive phenotypes of the progesterone receptor null mutant mouse Joumal of Steroid Biochemistry 56 67-77

Malayer JR and Woods VM (1998) Expression of estrogen receptor and maintenance of hormone-responsive phenotype in bovine fetal uterine cells Domestic Animal Endocrinology 15 141-154

Marion GB and Gier HT (1971) Ovarian and uterine embryogenesis and morphology of the non-pregnant female mammal Journal of Animal Science Supplement 132 $24-47$

Marshall H, Morrison A, Studer M, Popperl H and Krumlauf $\mathbf{R}$ (1996) Retinoids and Hox genes FASEB Journal 10 969-978

Martal I, Chene N, Camous S, Huynh L, Lantier F, Hermier P, Haridon RL, Charpigy G, Charlier M and Chaouat G (1997) Recent developments and potentialities for reducing embryo mortality in ruminants: the role of IFN-t and other cytokines in early pregnancy Reproduction Fertility and Development 9 355-380

Moon RT, Brown JD and Torres M (1997) WNTs modulate cell fate and behavior during development Trends in Genetics $13157-162$

Moran C, Prendiville DJ, Quirke JF and Roche JF (1990) Effects of oestradiol, zeranol or trenbolone acetate implants on puberty, reproduction and fertility in heifers Journal of Reproduction and Fertility 89 527-536

Mori $\mathrm{T}$ and Nagasawa $\mathrm{H}$ (1988) Toxicity of Hormones in Perinatal Life CRC Press, Boca Raton, FL

Ohta $Y$ (1995) Sterility in neonatally androgenized female rats and the decidual cell reaction International Review of Cytology 160 1-52

Pavlova A, Boutin E, Cunha G and Sassoon D (1994) Msx1 (Hox$7.1)$ in the adult mouse uterus: cellular interactions underlying regulation of expression Development 120 $335-346$

Sananes N, Baulieu EE and Le Goascogne C (1980) Treatment of neonatal rats with progesterone alters the capacity of the uterus to form deciduomata Journal of Reproduction and Fertility 58 271-273

Smith CL (1998) Cross-talk between peptide growth factor and estrogen receptor signaling pathways Biology of Reproduction 58 627-632

Spencer TE, Wiley AA and Bartol FF (1993) Neonatal age and period of estrogen exposure affect porcine uterine growth, morphogenesis, and protein synthesis Btology of Reproduction $48741-751$

Spencer TE, Becker WC, George P, Mirando MA, Ogle TF and Bazer FW (1995) Ovine interferon- $t$ regulates expression of endometrial receptors for estrogen and oxytocin but not progesterone Biology of Reproduction 53 732-745

Stevenson KR, Gilmour RS and Wathes DC (1994) Localization of insulin-like growth factor-I (IGF-I) and -II messenger ribonucleic acid and type 1 IGF receptors in the ovine uterus during the estrous cycle and early pregnancy Endocrinology 134 1655-1664

Sugawara J, Fukaya T, Murakami T, Yoshida H and Yajima A (1997) Hepatocyte growth factor stimulates proliferation, migration, and lumen formation of human endometrial epithelial cells in vitro. Biology of Reproduction 57 936-942

Takahashi T, Eitzman B, Bossert NL, Walmer D, Sparrow K, Flanders KC, McLachlan J and Nelson KG (1994) Transforming growth factors beta 1 , beta 2 , and beta 3 
messenger RNA and protein expression in mouse uterus and vagina during estrogen-induced growth: a comparison to other estrogen-regulated genes Cell Growth and Differentiation 5 919-935

Tarleton BJ, Wiley AA, Spencer TE, Moss AG and Bartol FF (1998) Ovary-independent estrogen receptor expression in neonatal porcine endometrium Biology of Reproduction $\mathbf{5 8}$ 1009-1019

Taylor HS, Vanden Heuvel GB and Igarashi P (1997) A conserved Hox axis in the mouse and human female reproductive system: late establishment and persistent adult expression of the Hoxa cluster genes Biology of Reproduction 57 1338-1345

Torry DS and Torry RJ (1997) Angiogenesis and the expression of vascular endothelial growth factor in endometrium and placenta American Journal of Reproductive Immunology 37 21-29

Vallet JL, Christenson RK, Bartol FF and Wiley AA (1995) Effect of retinyl palmitate, progesterone, oestradiol, and tamoxifen treatment on secretion of a retinol binding protein-like protein during uterine gland development in neonatal swine fournal of Reproduction and Fertility 103 189-197

Wang W, Van De Water T and Lufkin T (1998) Inner ear and matemal reproductive defects in mice lacking the Hmx3 homeobox gene Development 125 621-634

Wiley AA, Bartol FF and Barron DH (1987) Histogenesis of the ovine uterus Journal of Animal Science 64 1262-1269

Winters TA, Febres GF, Fulgham DL, Bertics PJ, Duello TM and Gorski J (1993) Ontogeny of the epidermal growth factor receptor during development of the fetal bovine mesonephros and associated organs of the urogenital tract Biology of Reproduction 48 1395-1403

Wolfenson D, Bartol FF, Badinga L, Barros CM, Marple DN, Cummins KA, Wolfe DF, Lucy MC, Spencer TE and Thatcher WW (1993) Secretion of PGF and oxytocin during hyperthermia in cyclic and pregnant heifers Theriogenology 39 1129-1141.

Yoshizawa T, Handa Y, Uematsu Y, Takeda S, Sekine K, Yoshihara Y, Kawakami T, Arioka K, Sato H, Uchiyama Y, Masushige S, Fukamizu A, Masumoto T and Kata S (1997) Mice lacking the vitamin D receptor exhibit impaired bone formation, uterine hypoplasia and growth retardation after weaning Nature Genetics 16 391-396

Zhang Z, Laping J, Glasser S, Day P and Mulholland J (1998) Mediators of estradiol-stimulated mitosis in the rat uterine luminal epithelium Endocrinology 139 961-966 